\title{
Optimal Foraging and Beyond: How Starlings Cope with Changes in Food Availability
}

\author{
Luis M. Bautista, ${ }^{1, \star}$ Joost Tinbergen, ${ }^{2}$ Popko Wiersma, ${ }^{2}$ and Alex Kacelnik ${ }^{1}$
}

1. Department of Zoology, University of Oxford, Oxford OX1 3PS, United Kingdom;

2. Zoological Laboratory, University of Groningen, P.O. Box 14, 9750 AA Haren, The Netherlands

Submitted October 20, 1997; Accepted April 20, 1998

ABSTRACT: Foraging adaptations include behavioral and physiological responses, but most optimal foraging models deal exclusively with behavioral decision variables, taking other dimensions as constraints. To overcome this limitation, we measured behavioral and physiological responses of European starlings Sturnus vulgaris to changes in food availability in a laboratory environment. The birds lived in a closed economy with a choice of two foraging modes (flying and walking) and were observed under two treatments (hard and easy) that differed in the work required to obtain food. Comparing the hard with the easy treatment, we found the following differences. In the hard treatment, daily amount of work was higher, but daily intake was lower. Even though work was greater, total daily expenditure was smaller, partly because overnight metabolism was lower. Body mass was lower, but daily oscillation in body mass did not differ. Feces' caloric density was lower, indicating greater food utilization. Energy expenditure rate expressed as multiples of basal metabolic rate $(\mathrm{BMR})$ increased during the working period from $3.5 \times \mathrm{BMR}$ (easy) to $5.2 \times$ BMR (hard), but over the 24 -h period, it was close to $2.4 \times$ BMR in both treatments. We also found that rate of expenditure during flight was very high in both treatments $(52.3 \mathrm{~W}$ in easy and $45.5 \mathrm{~W}$ in hard), as expected for short (as opposed to cruising) flights. The relative preferences between walking and flying were incompatible with maximizing the ratio of energy gains per unit of expenditure (efficiency) but compatible with maximizing net gain per unit of time during the foraging cycle (net rate). Neither currency explained the results when nonforaging time was included. Time was not a direct constraint: the birds rested more than $90 \%$ of the time in both treatments. Understanding this complex picture requires reasoning with ecological, physiological, and

\footnotetext{
* To whom correspondence should be addressed; address for correspondence: Departamento de Ecología Evolutiva, Museo Nacional de Ciencias Naturales, CSIC, José Gutierrez Abascal 2, 28006 Madrid, Spain; E-mail: Imbautista@mncn.csic.es. Am. Nat. 1998. Vol. 152, pp. 543-561. (C) 1998 by The University of Chicago. 0003-0147/98/5204-0004\$03.00. All rights reserved.
}

cognitive arguments. We defend the role of optimality as an appropriate tool to guide this integrative perspective.

Keywords: energy budget, metabolic ceiling, metabolic rate, optimal foraging, starling, Sturnus vulgaris.

Animals under natural circumstances allocate time and effort to foraging for food. When food availability varies, individuals may react in many different ways. They may, for instance, modify the time allocated to foraging so as to collect the same daily amount of food regardless of the effort or time it takes to find it. They may reallocate time so as to gain the same net energy, taking into account the changes in expenditure across conditions. They may switch between high expenditure-high yield and low expenditure-low yield foraging modes so that neither the net rate of gain nor the daily foraging time change, but some cost is paid on another dimension such as predation risk or nutrient balance. Or they may take intermediate strategies.

All these behavioral responses are likely to influence fitness. First, different time allocations affect activities other than foraging, such as self-grooming or social interactions, as well as affecting exposure to predation if different activities have different risks. Second, energy turnover may influence fitness in the absence of changes in net rate of energy gain because of costs of digestion (Karasov 1986, 1990) or because of fitness costs associated with energy output (heat production, mechanical work, tissue maintenance; see Drent and Daan 1980; Schmid-Hempel et al. 1985; Masman et al. 1988). Physiological limits to energy budgets may be important factors in determining foraging behavior in the short term (e.g., hours or days in vertebrates; see Weiner 1992; Mauer 1996), but these physiological limits are themselves candidates to be modified by natural selection in the long term (e.g., Diamond and Hammond 1992; Ricklefs 1996).

These examples are only part of the battery of possible strategic responses to ecological circumstances. In addition to responding behaviorally, animals may use ana- 


\section{The American Naturalist}

tomical adaptations, for instance, by modifying gut structure (e.g., Dykstra and Karasov 1992). This could change the parameters of food absorption, trading nutritional selectivity against energetic utilization of foodstuffs. They may also adjust their physiology, controlling variables such as overnight metabolism. This may imply trading the fitness consequences of torporlike states against the gains from avoiding some of the daytime foraging that provides the energy for overnight metabolism. None of the costs and benefits of these different responses are well understood, but there is little doubt that a change in food availability can be tackled by a suite of responses of which behavior is only one.

Even though all of this is uncontroversial, formal modeling of foraging adaptations rarely crosses the boundaries between behavior and physiology. Optimality modeling in biology proceeds by defining a strategy set and then finding ways of ranking the members of the set in terms of some goal function or currency. Here we focus on potentially important elements of the strategy set that are not usually considered. Our interest is to put foraging currencies commonly used in optimal foraging theory in a more realistic context, with the hope that this would enrich research into foraging ecology.

Usual foraging currencies combine the gross rate of energy collected over time, the rate of energy expenditure over time ( $c$ for cost), and, less frequently, dimensions such as territorial defense, predation risks, or the variability rather than the average of these rates. Three currencies that are often contrasted are the gross rate of intake per se ( $b$ for benefit), the net rate $b-c$, and the energetic efficiency $b / c$ (for examples of direct empirical comparisons among them, see Kacelnik 1984; SchmidHempel et al. 1985; Ydenberg et al. 1994). Sometimes $b$ is evaluated after the digestive efficiency is considered, that is, excluding the fact that some of the food is not incorporated into the body but goes through as feces. This is still a "gross" gain because it does not incorporate the fact that obtaining food requires energy expenditure. To visualize the enormous difference that these sensible currencies can make to the prediction of preferences among food sources, consider a situation where an animal faces two food sources, one with $b=2 \mathrm{~W}$ and $c=$ $1 \mathrm{~W}$ and another with $b=10 \mathrm{~W}$ and $c=9 \mathrm{~W}$. From the point of view of gross rate of gain, the second source is five times as good as the first. From a net gain perspective, both sources yield a net difference of $1 \mathrm{~W}$ and thus have the same value. From the point of view of efficiency, the first situation is more favorable because it yields an efficiency of 2 while the second yields only about 1.1 (efficiency has no units) - and all of this without including the fact that the values of $b$ could be pre- or postabsorptive. Thus, a priori arguments could be raised to support expectations for preferring either food source or being neutral and, more perniciously, post hoc arguments could be proposed after any display of preference if one were to defend the case that the animal's decisions are adaptive. The reasoning about which currency is most appropriate in each case must be supported by independent analysis of each ecological and physiological scenario. It is unlikely that maximizing gross rate per se would yield higher fitness gains than maximizing net gains in many circumstances. Theoretically, maximizing $b-c$ is likely to be a good predictor of behavior when fitness is only limited by energy balance and level of expenditure per se is inconsequential. Efficiency, on the other hand, could be related closely to fitness if expenditure is meaningful by itself. These points have been extensively discussed by many authors before (Krebs and Kacelnik 1984; Schmid-Hempel et al. 1985; Stephens and Krebs 1986; Ydenberg et al. 1994; Houston 1995), but they are important in the context of this study because we intend to explore experimentally some of their simplifying assumptions and because we wish to illustrate how optimality thinking can play an important heuristic role even when all simple models derived from it fail to account for the different facets of the data.

In this article, we report foraging experiments with captive starlings (Sturnus vulgaris) in a relatively rich laboratory environment that simulates some aspects of central-place foraging in the wild. Starlings are central-place foragers during the breeding season. They visit widely dispersed patches between visits to their nests and switch patches regularly (Tinbergen 1981). Often they face choices among foraging modes with different costs and yield, such as catching flying insects by hawking, picking insects from the tip of grasses as they walk, or probing the ground for insect larvae or earthworms. In deterministic situations (i.e., excluding problems of unpredictability or incomplete information), net rate of energy gain by the foraging parents or by the assemblage of parent plus brood has often been found to be a good predictor of starling behavior (Kacelnik and Houston 1984; Kacelnik et al. 1986; Kacelnik and Cuthill 1987), but they may switch to other criteria under a variety of scenarios (Houston 1987, 1995; Ydenberg et al. 1994; Bateson and Kacelnik 1996; Koops and Giraldeau 1996).

In our experimental situation, the starlings had to visit a central place where they faced a choice between obtaining food using either of two foraging modes, flying and walking. Flying yielded a higher gross rate of gain than walking but also implied a higher rate of expenditure. We used a titration procedure, fixing the number of flights per reward but modifying the amount of walking per food item in the walking option until the birds showed equal use of both modes. We then used the point 
of equilibrium to evaluate putative algorithms that might emulate the outcome of the psychological processes that the birds use to make choices. In addition to these behavioral dimensions, we measured several indices of digestive physiology, including body mass regulation.

The aim is to address the following questions, which are admittedly nonindependent. How do changes in food availability affect total daily time spent foraging? Does change in foraging behavior result in homeostatic control of either gross or net intake over the 24-h cycle? Is body mass regulated homeostatically or strategically (i.e., in relation to predominant foraging mode)? Do starlings reallocate energy expenditure at nonforaging times of the daily cycle to respond to changing foraging costs? Can the choice between foraging modes be explained using a simple combination of rates of gain and expenditure such as net rate of gain or energetic efficiency?

Estimates of physiological parameters relevant to these questions such as digestive assimilation (Al Jaborae 1979; Connors and Nickol 1991; Levey and Karasov 1994) or basal metabolic rates (Dmi'el and Tel-Zur 1985; Connors and Nickol 1991) have been measured in the laboratory for this species, while factors that affect energy expenditure during flight, foraging, and resting have been measured in the wild (e.g., Ricklefs and Williams 1984; Westerterp and Drent 1985). This makes it possible to make quantitative predictions for many aspects of foraging, but measuring these parameters simultaneously in one experimental system is still necessary, as costs of activities such as flying or sleeping do not always translate well between different situations. One of the goals of this study was to estimate the parameters required to test the predictions of energetic currencies in the same system in which the behavioral choices take place.

\section{Material and Methods}

We used seven wild-caught starlings as main subjects and housed them in individual aviaries in the Zoological Laboratory, University of Groningen, The Netherlands. Eight additional birds were used for control measurements as indicated below. Throughout the main experiment, the subjects were visually but not acoustically isolated and lived in the experimental aviaries, which measured $5 \mathrm{~m}$ long $\times 2 \mathrm{~m}$ high $\times 0.5 \mathrm{~m}$ wide (fig. $1 A$ ). Each aviary had three perches, one central and two "foraging" ("near" and "distant"), all of them with microswitches that sensed when the birds landed or were sitting on them. The central perch was placed $0.35 \mathrm{~m}$ from the near perch and $4.65 \mathrm{~m}$ from the distant perch. There was a platform that made it possible to walk between the central and near perches but not between the central and the distant perch, which could be reached only by flying. All three perches were $1.30 \mathrm{~m}$ above the floor. Fresh drinking water was always available in bottles located by the near and distant perches. Food consisted of a mixture by weight of $90 \%$ turkey starter crumbs (Dodson \& Horrell, Ringstead) and 10\% Orlux (a Belgian commercial food for birds). Food rewards with a mean weight of $0.09 \mathrm{~g}$ (gross caloric content of $1.6 \mathrm{~kJ}$ ) were delivered to a hopper in front of the foraging perches (FEEDER, fig. 1) used to obtain that reward.

\section{Daily Routine}

The birds were on a photoperiod of 12L:12D. The dark period started at 2030 hours and ended at 0830 hours. The change from dark to light was gradual. Between 0830 and 0915 hours, we captured the birds and weighed them to the nearest $0.01 \mathrm{~g}$ to record their morning body mass $\left(\mathrm{BM}_{\mathrm{am}}\right)$, recovered the excrements, cleaned the cages, and measured the amount of water $( \pm 0.01 \mathrm{~g})$ that had been drunk since 1715 hours of the previous day. Food was available through the working schedule described below between 0915 and 1715 hours, when the foraging schedule was stopped and the birds were caught, weighed to record the evening body mass $\left(\mathrm{BM}_{\mathrm{pm}}\right)$, and water consumption recorded. Three mealworms were provided daily, and a water bath was available for $30 \mathrm{~min}$ each day.

\section{Foraging Schedule}

The birds were trained to gain each food reward by flying or walking a number of times between the central perch and either the distant or near perches until food was delivered. A BBC microcomputer running SPIDER software (CeNeS Cognition 1990) ran the schedule and stored the data. Lights placed next to each perch guided the birds through the schedule. Only perches with their lights on were primed to receive responses. Typically, when the bird landed on a primed perch, its light went off and the schedule advanced, either by delivering a reward or by indicating with other lights which perch or perches were now ready.

We use the term cycle for describing the events required to obtain a reward. There were "forced" and "free" cycles. In forced cycles only one of the foraging perches was active until a reward was collected so that the animal could not choose whether to walk or to fly for its food, while in free cycles the birds could choose which foraging mode to use. A forced cycle started as the bird first landed on the primed central perch after consuming the previous reward. The central perch light switched off and the light at one of the two foraging perches switched on. When the bird landed on the primed foraging perch, its light switched off and the central perch was primed 


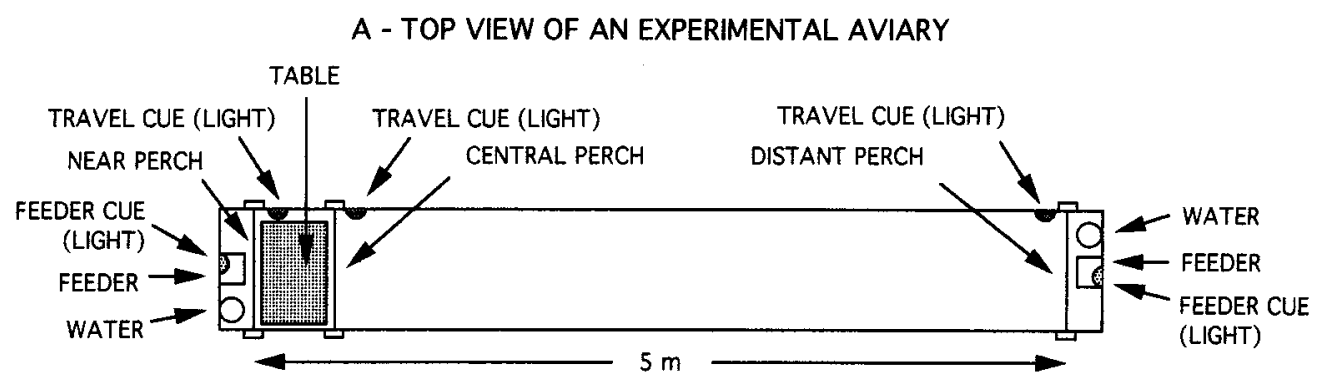

B - EXPERIMENTAL SCHEDULE

\begin{tabular}{|c|c|c|c|c|c|}
\hline & \multicolumn{4}{|c|}{ FORAGING TRIAL. } & \\
\hline & \multicolumn{2}{|c|}{ FORCED BLOCK } & \multicolumn{2}{|c|}{ FREE BLOCK } & \\
\hline & FORCED CYCLE & FORCED CYCLE & FREE CYCLE & FREE CYCLE & \\
\hline
\end{tabular}

Figure 1: A, Top view of an experimental aviary. An elevated platform (table) was located between the central perch and the "near" perch to allow birds to walk between them. The birds had to fly between the "distant" perch and the central perch. $B$, Schematic overview of the experimental design, including the terminology. The time course is from left to right. Each cycle consists of a number of flights or walks resulting in a food reward. A food reward was delivered after walking between the central perch and the near perch $m$ times or after flying between the central perch and the distant perch $n$ times. The arrows in $B$ show the time course of the foraging cycles. In forced blocks, there were one flying cycle and one walking cycle in random order. For instance, a first reward was obtained after flying $n$ times between the central and distant perches and then a second reward was obtained after walking $m$ times between the central and near perches. Free blocks started when the subject selected either the near perch (walk) or the distant perch (fly). The number of walks per reward $(m)$ was modified by $10 \%$ between trials, depending on whether, in the two free cycles, the bird chose to walk (new $m=1.10 \times$ old $m$ ), to fly (new $m=0.90 \times$ old $m$ ), or one of each, respectively (new $m=1.00 \times$ old $m$ ). See "Material and Methods" for further details.

again. After a preset number of repetitions had taken place, a light next to the feeder corresponding to the foraging perch used in that cycle was switched on for $5 \mathrm{~s}$ while the food dispenser delivered the reward. Subsequently, the central perch was primed to allow for a new cycle to start. In a free cycle, the central place was primed in the same form after a reward, but once the bird landed on it both foraging perches were primed. The first visit to one of them expressed the subject's choice, and from then on, the cycle continued as in forced cycles, with only the chosen foraging perch primed on every visit to the central place. Two consecutive cycles formed a "block," and two consecutive blocks (i.e., four cycles) a "trial." The whole protocol is shown schematically in figure $1 B$.

The first two cycles of each trial were forced (one walking, one flying, in random order), forming a forced block in which the bird experienced the current values of the schedule. The two subsequent cycles were free, form- ing a free block in which the subjects expressed their preference walking and flying.

\section{Treatments}

There were two treatments called easy and hard according to how much work was necessary to collect one food reward. In order to do this while allowing some choice of foraging mode, we only varied the number of flights required per reward in each treatment and allowed the number of walks to be determined by the animals' preferences as described below. Both treatments started by setting the number of flights at the required value for that treatment and the number of walks per reward at one. In the easy treatment, the number of flights per reward was always two, yielding a gross gain of $0.403 \mathrm{~kJ}$ per flight. In the hard treatment, we initially fixed a value of nine flights per reward but had to lower this number for some birds in order to allow them to keep a stable body 
mass (yielding a mean $0.103 \mathrm{~kJ}$ per flight after body mass stabilized).

The number of walks was adjusted between trials as follows. If the bird used the flying mode in both free cycles, the number of walks per reward programmed for the next trial decreased by the closest integer approximation to $10 \%$ (to a minimum of one walk per reward). If the bird walked in both free cycles, the number of walks per reward was increased by $10 \%$ (no maximum). No change occurred if the bird had walked in one cycle and flown in the other. As we will discuss later, the number of walks that are equivalent in value to a set number of flights depends on the currency used. Our procedure permits using the point of equilibrium reached by the animals to determine the equivalence between walks and flights from the starling's point of view, giving an indication of the currency that governs the birds' foraging choices.

Each treatment ran for $23 \mathrm{~d}$ on average (range 17-31 d) until body mass, daily intake, and the number of walks stabilized. The duration of the experiments is critical because different adaptive responses have different time courses. The value of digestive constraints can only be estimated by simultaneous measurements of energy expenditure and assimilation over a sufficiently long period (Weiner 1987, 1992; Dykstra and Karasov 1992) because high daily energy expenditures may be systematically compensated by a much lower energy expenditure immediately before or after the period of observation (see Bryant and Tatner 1991). We considered stabilization achieved if there was no significant daily variation in the mean of these variables during six consecutive days and used these days for analysis.

Three birds experienced the easy treatment first and four birds experienced the opposite order. For each day, we recorded the number of foraging trials, the number of walks per reward of each trial, the intake achieved from flying, and the intake achieved from walking (grams) and the total flight and walking distance (meters). Temperature was not controlled, but maximum and minimum room temperature $\left({ }^{\circ} \mathrm{C}\right)$ were recorded. Since the computer only recorded activity according to landings on primed perches, we also sampled the number of flights and walks by direct observation. Flights and walks between the perches after the working period were recorded by the computer and added to the distances traveled each day.

\section{Time Budgets}

Flight and walk velocities in these cages as measured in a different experiment (L. M. Bautista, A. Kacelnik, and
J. M. Tinbergen, unpublished manuscript) were $4.31 \pm$ $0.26 \mathrm{~m} / \mathrm{s}$ and $0.69 \pm 0.25 \mathrm{~m} / \mathrm{s}( \pm 1 \mathrm{SD})$, respectively, with no significant effects of foraging schedule or body mass on either of the two velocities. We used these values to calculate the total time spent flying and walking per day. Daily flying time was calculated in seconds as $T_{\mathrm{f}}=n_{\mathrm{f}} \times 2 \times R_{\mathrm{f}} \times t_{\mathrm{f}}$, where $n_{\mathrm{f}}$ is the number of rewards obtained flying during the day, $R_{\mathrm{f}}$ is the number of flights from the central perch per reward, and $t_{f}$ is the time of a single flight between the central and distant perches in seconds. The figure is doubled to include return flights. Total time spent walking per day was calculated in seconds as $T_{\mathrm{w}}=n_{\mathrm{w}} \times 2 \times \bar{R}_{\mathrm{w}} \times t_{\mathrm{w}}$, where $n_{\mathrm{w}}$ is the number of rewards obtained walking during the day, $\bar{R}_{\mathrm{w}}$ is the daily mean of the number of walks per reward, and $t_{\mathrm{w}}$ is the time of a single walk between the central and near perches in seconds. Note that $R_{\mathrm{w}}$ may change between foraging trials due to the titration. Total daily travel time $\left(T_{\mathrm{T}}\right)$ was calculated as $T_{\mathrm{T}}=T_{\mathrm{f}}+$ $T_{\mathrm{w}}$. Notice that due to the forced trials, $n_{\mathrm{f}}$ and $n_{\mathrm{w}}$ are not independent. This will become important in data analysis.

\section{Control Group}

A control group of eight birds was kept in small cages $(40 \mathrm{~cm} \times 40 \mathrm{~cm} \times 90 \mathrm{~cm})$. These birds experienced the same daily routine as the experimental birds, being weighed twice a day at the same times, before and after food was available. Food was offered ad lib. from 0930 to 1730 hours. Spilled food was recovered and separated from the excrement before food consumption was estimated. Water was given ad lib. and three mealworms (0.07 kJ each, see Moore and Simm 1985) added at the end of each day. The dark-light schedule and temperature were equivalent to those experienced by the main experimental group.

\section{Energy Measurements}

The standard equation for a daily energy budget is $\mathrm{Ik}=$ $\mathrm{Re}+\mathrm{Pr}+\mathrm{Ex}$, where Ik (intake) is the energy consumed as food, Re (respiration) is the energy expenditure, $\operatorname{Pr}$ (production) is the energy stored or lost as body mass, and Ex is the energy lost in urine and feces. Energy expenditure Re can be estimated as Ik $\mathrm{Ex}-\mathrm{Pr}$, and if body mass and water content are stable $(\operatorname{Pr}=0)$, this reduces to the metabolized energy $(\mathrm{ME}=\mathrm{Ik}-\mathrm{Ex}$, kilojoules/day). To allow further comparisons between treatments, we express energy expenditure by computing multiples of basal metabolic rates $(\times$ BMR, defined below) as measured in each treatment. 


\section{The American Naturalist}

Energy Intake and Production. Energy intake (Ik, kilojoules/day) was estimated from the rewards delivered. Energy density of the food was measured in a bomb calorimeter after drying the food sample for $48 \mathrm{~h}$ at $60^{\circ} \mathrm{C}$. Energy stored (Pr, kilojoules/day) was estimated from the difference in morning body masses between days. The energetic equivalence of body mass change was assumed as $19.2 \mathrm{~kJ} / \mathrm{g}$ (Masman 1986).

Energy excreted (Ex) was estimated by collecting the excrements from plastic sheets covering the floor of aviaries and cages. After drying the excrements in a stove at $60{ }^{\circ} \mathrm{C}$ for $48 \mathrm{~h}$, we weighed them to the nearest $0.0001 \mathrm{~g}$ and measured their energy density (kilojoules/gram) in an oxygen bomb calorimeter.

Nocturnal Energy Expenditure. Nocturnal energy expenditure was measured as oxygen consumption and $\mathrm{CO}_{2}$ production in an open air flow system from 2030 hours until 0830 hours. Sample subjects sat on a perch in a sealed Plexiglas box of $24 \mathrm{~L}$ in darkness. The box was in a temperature-controlled room set so that temperature within each box was kept within the thermoneutral zone: $20.9^{\circ} \mathrm{C} \pm 6.0^{\circ}$ in easy and $19.9^{\circ} \mathrm{C} \pm 6.3^{\circ}$ in hard, ranging from $14^{\circ}$ to $29^{\circ} \mathrm{C}$ (Biebach 1979, 1981, 1984; but see Dmi'el and Tel-Zur 1985). An air flow of $100 \mathrm{~L} / \mathrm{h}$ was pumped through the box. Flow rate was measured with a mass-flow controller (Type 5850E, Brooks Veenendaal, The Netherlands). In-going and out-flowing air were dried over a molecular sieve ( $3 \AA$, Merck, Darmstadt). Gas analyses were done with a zirconium oxide analyzer (Ametek S3A/II Applied Electrochemistry, Pittsburgh) to an accuracy of $0.01 \%$, and $\mathrm{CO}_{2}$ concentrations with an infrared beam $\mathrm{CO}_{2}$ analyzer (Binos, Leybold Heraeus, Hanau). All outputs were recorded at 6-min intervals. Oxygen consumption was calculated according to Hill (1972). The energy equivalent of oxygen consumption was assumed to be $19.9 \mathrm{~kJ} / \mathrm{L} \mathrm{O}_{2}$ (Hill 1972). It was not possible to measure nocturnal metabolism for all birds every night. We measured four birds from the control treatment once; we took nine measurements of birds from the easy treatment and 11 measurements of birds from the hard treatment, with some birds measured more than once. Basal metabolic rate (BMR) was calculated as the minimum value of a 30 -min running mean of oxygen consumption. To compare treatments, we calculated mass-specific BMR by averaging the body masses measured when the bird was placed in and removed from the respirometer.

Daytime Energy Expenditure. Energy expenditure during the working period was measured once in each bird in both treatments using doubly labeled water (Lifson and McClintock 1966). The relationship between short-term energy expenditure and daily energy expenditure may be obscured by variations in the time budget (Ricklefs et al. 1996) and because birds may compensate for periods of high energy expenditure by reducing their metabolism during the resting time (Tiebout 1991). To increase the accuracy of our estimates of working energy costs, we did not sample over a 24 -h period but over the working period only (approximately $8 \mathrm{~h}$ ). Mean biological half-lives based on ${ }^{18} \mathrm{O}$ were $1.50 \pm 0.65$ and the biological half-life of deuterium was on average $89 \% \pm 2.8 \%$ of that of ${ }^{18} \mathrm{O}$, meeting the requirements with regard to precision as formulated by Nagy (1980). The ${ }^{18} \mathrm{O}$ enrichments of the final samples were on average 0.077 atom percentage \pm 0.031 above the background level, sufficiently high to allow accurate measurement.

Birds were caught at 0730 hours while sleeping, weighed, injected with $0.25 \mathrm{~mL}$ of a mixture of doubly labeled water containing $12.79 \mathrm{~g}$ of $90 \% \mathrm{AP} \mathrm{H}_{2}{ }^{18} \mathrm{O}$ and $5.66 \mathrm{~g}$ of $99.9 \% \mathrm{AP} \mathrm{D}_{2} \mathrm{O}$, and placed in small boxes (30 $\mathrm{cm} \times 30 \mathrm{~cm} \times 30 \mathrm{~cm}$ ). They were then left at rest for at least $1 \mathrm{~h}$ to allow an even distribution of the isotopes in the body fluid (Williams and Nagy 1984; Williams 1985). An hour after the injection, they were weighed again and the initial blood samples (each sample comprised by up to five capillary tubes of $10 \mu \mathrm{L}$ each) were taken from the brachial vein. At approximately 1730 hours, after the working period, the birds were recaptured and the final blood samples were taken (each sample comprised by up to five capillary tubes of $30-60 \mu \mathrm{L}$, each one holding about $10 \mu \mathrm{L})$. To reduce the amount of blood that had to be sampled from the same bird, background measurements of both ${ }^{18} \mathrm{O}$ and deuterium concentrations were estimated using blood from the control subjects. All blood samples were collected in glass capillaries sealed immediately after sampling. Concentrations of ${ }^{18} \mathrm{O}$ and deuterium in the blood were determined at the Center of Isotope Research of the University of Groningen, The Netherlands, by mass spectrometry (see Masman and Klaassen 1987).

Estimates of energy expenditure based on the $\mathrm{CO}_{2}$ production were calculated according to Lifson and McClintock (1966), using the respiration quotient (RQ) measured in the respirometer and an energy equivalent of $19.9 \mathrm{~kJ} / \mathrm{L} \mathrm{O}_{2}$. Body water volume was deduced from the dilution space of ${ }^{18} \mathrm{O}$ (Schoeller et al. 1980).

\section{Foraging Currencies}

For each foraging mode (walking and flying), two currencies were calculated: efficiency and net rate. Net rate was computed as the difference between the rate of gross energy intake $(b)$ and the rate of energy expenditure $(c)$. We did not distinguish between components of the ex- 
creta derived from nonabsorbed food and from metabolized renal products, hence, it is not possible to be precise in correcting gross rate of gain to take into account digestive efficiency. We approximated this by calculating rate of gross energy intake as the energy gain per cycle duration $\left(V_{\mathrm{p}} / t_{\mathrm{c}}\right)$, where $V_{\mathrm{p}}$ is the energy content of a reward (joules) multiplied by the apparent metabolizable energy coefficient, and cycle duration $\left(t_{c}\right)$ is the time spent in travel plus the time spent handling the food (seconds). Time spent in travel included the duration of flights or walks and the duration of each landing episode on perches. Mathematically, this is expressed as $t_{\mathrm{c}}=$ $2 r(t+p)+h$, where $r$ is the number of preset travels between the central perch and the foraging perch (doubled to include return trips), $t$ is the duration of a single travel (i.e., the time in the air or actually walking), $p$ is the time perching between consecutive travels, and $h$ is the time spent handling and eating the reward.

Rate of energy expenditure $(c)$ is calculated as the energy expenditure per cycle duration $\left(e_{\mathrm{x}} / t_{\mathrm{c}}\right)$, where $e_{\mathrm{x}}$ is the energy expenditure calculated as the sum of expenditures while traveling, landing, and handling the reward (joules). This is given by $e_{\mathrm{x}}=2 r\left(t c_{\mathrm{t}}+p c_{\mathrm{p}}\right)+h c_{\mathrm{p}}$, where $c_{\mathrm{t}}$ is the energy expenditure rate of flying or walking and $c_{\mathrm{p}}$ is the energy expenditure rate of perching (joules/second). We assume that the cost of handling equals the cost of perching.

Replacing gross intake rate and energy expenditure rate by their mathematical expressions and rearranging the terms, net rate $(b-c)$ is computed as $\left\{V_{\mathrm{p}}-\left[2 r\left(t c_{\mathrm{t}}+p c_{\mathrm{p}}\right)+h c_{\mathrm{p}}\right]\right\} /[2 r(t+p)+h]$ with dimensions of energy over time (joules/second). Efficiency $(b / c)$ is computed as $V_{\mathrm{p}} /\left[2 r\left(t c_{\mathrm{t}}+p c_{\mathrm{p}}\right)+h c_{\mathrm{p}}\right]$, with no dimensions.

\section{Results}

\section{Body Mass and Food Intake}

Our criterion for stability in each treatment was lack of significant variation of body mass (BM) over six consecutive days. If body mass is constant and body composition is assumed to be stable, then production of new tissue may be considered null and a number of inferences can be made from energy intake and excretion.

Body mass stability in the hard treatment was not achieved for some birds at the preselected ratio of nine flights per reward. Because of this, we reduced the ratio for those birds until all of them reached stability. Under the conditions in which all birds reached the stability criterion, mean $( \pm 1 \mathrm{SD})$ number of flights per reward under hard was $7.8 \pm 1.1$. There was no significant daily mass change over the last $6 \mathrm{~d}$ neither in the easy treatment nor in the hard treatment (Spearman rank correla-

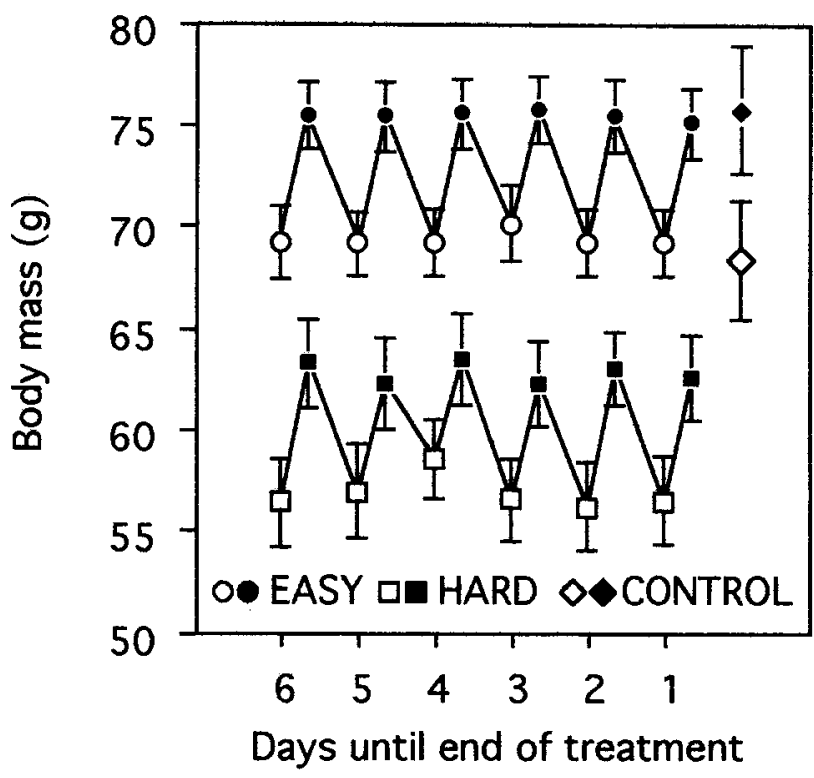

Figure 2: Body mass at the start (open symbols) and end ( filled symbols) of the foraging period during the last $6 \mathrm{~d}$ in the easy (circles) and the hard (squares) treatment. Each point gives the mean \pm SE of seven birds, except on day 4 in the hard treatment and on day 3 in the easy treatment, where six birds were weighed. The control group of eight different birds with food ad lib. is depicted by the diamonds.

tion between $\mathrm{BM}_{\mathrm{am}}$ and date, calculated for each bird and each treatment, all $P>.05$ ), indicating that birds were able to maintain body mass in both treatments (fig. 2). Figure 2 shows the body masses recorded during the stability period.

There was a significant effect of treatment on body mass (table 1). Both $\mathrm{BM}_{\mathrm{am}}$ and $\mathrm{BM}_{\mathrm{pm}}$ were greater in easy than in hard treatments, but there was no significant difference between treatments in the amplitude of the daily oscillation of body mass $\left(\mathrm{T}^{+}=12, P=.41\right.$, Wilcoxon signed rank test $\mathrm{T}^{+}$; Siegel and Castellan 1988). There were no significant differences in body mass between easy and control birds.

\section{Water Consumption}

Birds drank more water in the hard than in the easy treatment. This was due to a higher water consumption during the working period (table 1). Outside the working period, the water intake did not differ significantly between treatments and was very similar to that of the control birds. We have no information on how this differential drinking might have related to body or excrement composition, but the effect is more likely to reflect water loss due to the amount of flying than differences in the production of tissue or in the water content of the body. 


\section{The American Naturalist}

Table 1: Body mass (BM) before ( $\mathrm{am})$ and after $(\mathrm{pm})$ the active period and water ingested for eight starlings with food ad lib. (control) and seven starlings under two working regimes (easy and hard, see "Material and Methods")

\begin{tabular}{lcccc}
\hline & & & \multicolumn{2}{c}{ Water ingested $(g)$} \\
\cline { 3 - 4 } Treatments & $B M_{a m}$ & $\begin{array}{c}\text { Working } \\
(g)\end{array}$ & $\begin{array}{c}\text { Resting } \\
\text { period }\end{array}$ & $\begin{array}{c}\text { period } \\
\text { Control }\end{array}$ \\
Easy & $68.4 \pm 8.4$ & $75.6 \pm 8.7$ & $52.0 \pm 13.8$ & $10.7 \pm 4.7$ \\
Hard & $69.3 \pm 4.4$ & $75.6 \pm 4.8$ & $48.0 \pm 10.0$ & $13.7 \pm 6.8$ \\
Difference $(\%)^{\mathrm{a}}$ & $56.4 \pm 5.7$ & $63.0 \pm 6.1$ & $90.7 \pm 32.9$ & $11.7 \pm 4.2$ \\
& $-19^{*}$ & $-17^{*}$ & $88^{*}$ & $-3^{\mathrm{b}}$ \\
\hline
\end{tabular}

Note: Data are the mean $\pm 1 \mathrm{SD}$.

${ }^{a}$ Difference between hard and easy $=[($ hard - easy $) /$ easy $] \times 100 \%$. The mean figures in the bottom row are the averages of individual differences, hence they cannot be obtained from the percentage change between mean results shown in the table.

${ }^{b}$ NS, $P>.05$; Wilcoxon signed rank test $T^{+}$for paired data (Siegel and Castellan 1988).

${ }^{\star} P<.02$; Wilcoxon signed rank test $T^{+}$for paired data (Siegel and Castellan 1988).

Body mass in the hard treatment was lower than in the easy treatment even though water intake was higher.

\section{Food Energy Utilization}

In agreement with the stability of daily oscillations in weight (fig. 2), daily food intake was also stable over the last $6 \mathrm{~d}$ of each treatment. There were no significant differences between daily food intake in the easy treatment and in the control group (table $2 ; \mathrm{W}_{\mathrm{x}}=44, P=.19$, Wilcoxon-Mann-Whitney test $\mathrm{W}_{\mathrm{x}}$; Siegel and Castellan 1988), but intake in the easy treatment was higher than in the hard treatment $\left(\mathrm{T}^{+}=28, P<.01\right)$.

There was less energy in the excreta in the hard treatment than in the easy and control groups (table 2). The ratio of dry matter excreted over dry matter ingested varied from 0.62 to 0.48 in the easy and hard treatments, respectively, but this difference was not statistically reliable $\left(\mathrm{T}^{+}=25, P=.08\right)$. We observed sporadic coprophagic behavior in the hard and not in the easy treatment, but the quantitative significance of this could not be evaluated.

\section{Nocturnal Energy Expenditure}

Respirometry analysis from a sample of nights showed a significant reduction in energy consumed during the night in the hard treatment (table 3). Predictions of the BMR using individual $\mathrm{BM}_{\mathrm{am}}$ and the Aschoff and Pohl (1970) equation for the inactive phase were $0.77 \pm 0.04$

Table 2: Utilization of food energy content for eight starlings with food ad lib. (control) and seven starlings that experienced two food encounter rates (easy and hard, see "Material and Methods")

\begin{tabular}{|c|c|c|c|c|c|c|c|}
\hline \multirow[b]{3}{*}{ Treatment } & \multirow{3}{*}{$\begin{array}{l}\text { Dry intake } \\
(g / d)\end{array}$} & \multicolumn{3}{|c|}{ Excrement } & \multirow{3}{*}{$\begin{array}{c}\text { Apparent } \\
\text { metabolizable } \\
\text { energy } \\
\text { coefficient }\end{array}$} & \multirow{2}{*}{\multicolumn{2}{|c|}{ Metabolized energy }} \\
\hline & & \multirow{2}{*}{$\begin{array}{c}\text { Dry } \\
\text { matter } \\
(g / d)\end{array}$} & \multirow{2}{*}{$\begin{array}{c}\text { Ash } \\
\text { content } \\
(\%)\end{array}$} & \multirow{2}{*}{$\begin{array}{l}\text { Caloric } \\
\text { density } \\
(\mathrm{kJ} / \mathrm{g})\end{array}$} & & & \\
\hline & & & & & & $\mathrm{kJ} / \mathrm{d}$ & $\times B M R^{\mathrm{a}}$ \\
\hline Control & $16.7 \pm 2.2$ & $9.9 \pm 1.5$ & $6.3 \pm .5$ & $16.26 \pm .76$ & $.48 \pm .10$ & $154 \pm 41$ & $2.6 \pm .4$ \\
\hline Easy & $14.9 \pm 3.4$ & $9.3 \pm 2.7$ & $9.1 \pm .9$ & $16.12 \pm .71$ & $.52 \pm .04$ & $144 \pm 25$ & $2.3 \pm .5$ \\
\hline Hard & $9.0 \pm 1.8$ & $4.3 \pm 1.1$ & $10.4 \pm 1.1$ & $15.33 \pm .38$ & $.63 \pm .11$ & $107 \pm 30$ & $2.5 \pm .5$ \\
\hline Difference $^{\mathrm{b}}(\%)$ & $-36^{\star}$ & $-52^{\star}$ & $15^{\star}$ & $-5^{\star}$ & $26^{*}$ & $-25^{\star}$ & $16^{c}$ \\
\hline
\end{tabular}

Note: Food caloric density was $19.5 \mathrm{~kJ} / \mathrm{g}$ dry mass. Figures are the mean $\pm 1 \mathrm{SD}$. The apparent metabolizable energy coefficient was calculated as (energy intake - energy excreted)/energy intake, with the energy terms expressed in $\mathrm{kJ} / \mathrm{d}$.

${ }^{a}$ Basal metabolic rates (BMR) are given in table 3.

${ }^{\mathrm{b}}$ Difference between hard and easy $=[($ hard - easy $) /$ easy $] \times 100 \%$. The mean figures at the bottom are the averages of individual differences, hence, they do not match the percentage change between the mean results.

${ }^{c}$ NS, $P>.05$; Wilcoxon signed rank test $T^{+}$for paired data (Siegel and Castellan 1988).

${ }^{\star} P<.05$; Wilcoxon signed rank test $T^{+}$for paired data (Siegel and Castellan 1988). 
Table 3: Body mass (BM), basal metabolic rate per individual (BMR), basal metabolic rate per gram (BMR/BM), and respiration quotient $(\mathrm{RQ})$ measured in the respirometer in a sample of nights for each treatment $(n)$

\begin{tabular}{lccccc}
\hline Treatments & $\mathrm{n}^{\mathrm{a}}$ & $B M(g)$ & $B M R(W)$ & $B M R / B M(W / g)$ & $R Q$ \\
\hline Control & 4 & $63.0 \pm 4.9$ & $.814 \pm .074$ & $.0130 \pm .0019$ & $.78 \pm .01$ \\
Easy & 9 & $65.6 \pm 5.2$ & $.763 \pm .130$ & $.0116 \pm .0015$ & $.84 \pm .04$ \\
Hard & 11 & $52.3 \pm 6.3$ & $.493 \pm .076$ & $.0095 \pm .0016$ & $.90 \pm .02$ \\
Difference $^{\mathrm{b}}(\%)$ & & $-20^{\star * *}$ & $-35^{\star *}$ & $-18^{\star *}$ & $7^{\star *}$ \\
\hline
\end{tabular}

Note: Data are means $\pm 1 \mathrm{SD}$.

${ }^{a}$ Nights were sampled randomly among subjects.

${ }^{\mathrm{b}}$ Difference between hard and easy $=[$ (hard - easy $) /$ easy $] \times 100 \%$.

${ }^{* *} P<.01$; Wilcoxon-Mann-Whitney test $\mathrm{W}_{+}$(Siegel and Castellan 1988).

${ }^{* * *} P<.001$.

$\mathrm{W}$ in the easy treatment, close to our estimates (see table $3, \mathrm{~T}^{+}=22, P>.99$ ), but differed significantly from our estimates for the birds in the hard treatment $(0.65 \pm$ $\left.0.06 \mathrm{~W}, \mathrm{~T}^{+}=65, P<.01\right)$. This discrepancy is not surprising because the Aschoff and Pohl equation is derived empirically from between-species variations in body mass rather than from interindividual variations or variations within individuals across conditions. Higher RQ values showed that starlings in the hard treatment (table 3) used a larger proportion of carbohydrates to fuel their resting metabolism than in the easy treatment. However it is difficult to interpret the RQ value of 0.90 since $\mathrm{BM}_{\mathrm{am}}$ was stabilized and birds had no food in their guts when the nocturnal measures were recorded and were unlikely to store energy as carbohydrates to survive the night period.

\section{Daily Energy Expenditure}

Birds in the control and easy treatments did not differ significantly in metabolized energy (table $2, \mathrm{~W}_{\mathrm{x}}=51$, $P=.31$ ), but those in the hard treatment used significantly less energy per day (table 2). This drop in expenditure is interesting given that the total amount of work in the form of time spent traveling was greater in the hard than in the easy treatment (see "Time Budgets" below). Transforming the ME obtained in table 2 from intake and excretion measurements into watts and dividing by the value of BMR obtained by respirometry during the night, it is possible to express energy expenditure as multiples of BMR over the $24 \mathrm{~h}$ period. Notice that our data for night metabolism show that a different value of BMR must be used in different conditions, a correction that field studies of energy expenditure do not include. The average daily energy expenditure rate expressed as multiples of BMR did not differ significantly between treatments (table 2).
Table 4: Mass gain, water influx, and energy expenditure while foraging measured by doubly labeled water for seven starlings under two working regimes (easy and hard, see "Material and Methods")

\begin{tabular}{lccccc}
\hline & \multirow{2}{*}{$\begin{array}{c}\text { Mass gain } \\
\text { Treatment }\end{array}$} & $(\mathrm{g} / 8 \mathrm{~h})$ & $(\mathrm{mL} / 8 \mathrm{~h})$ & $\mathrm{kJ} / 8 \mathrm{~h}$ & $\times B M R$ \\
\hline Easy & $6.2 \pm 1.7$ & $53.1 \pm 9.7$ & $85.2 \pm 18.0$ & $3.5 \pm .8$ \\
Hard & $4.9 \pm 2.0$ & $83.3 \pm 33.2$ & $83.4 \pm 20.0$ & $5.2 \pm 1.0$ \\
$\begin{array}{l}\text { Difference } \\
\quad \%(\%)\end{array}$ & $-9^{\mathrm{b}}$ & $61^{*}$ & $-3^{\mathrm{b}}$ & $57^{\star}$ \\
\hline
\end{tabular}

Note: Data are means $\pm 1 \mathrm{SD}$.

${ }^{\text {a }}$ Difference between hard and easy $=[($ hard - easy $) /$ easy $] \times 100 \%$. The mean figures at the bottom are the averages of individual differences, hence, they do not match the percentage change between the mean results.

${ }^{\mathrm{b}} \mathrm{NS}, P>.05$; Wilcoxon signed rank test $T^{+}$for paired data (Siegel and Castellan 1988).

${ }^{*} P<.05$; Wilcoxon signed rank test $T^{+}$for paired data (Siegel and Castellan 1988).

\section{Daytime Energy Expenditure}

There was no significant difference between treatments in energy expenditure during the foraging period, as measured with doubly labeled water (approximately $84 \mathrm{~kJ} / 8$ $\mathrm{h}$, table 4). However, due to the changes in BMR (table 3 ) this translates into a significant difference in energy expenditure rate when expressed as multiples of mean BMR estimated for each treatment $(3.5 \times$ BMR and $5.2 \times$ BMR in the easy and hard treatments, respectively, table 4).

As an additional check on our figures, we estimated energy spent in the active period by an independent method. We subtracted estimates of energy spent at night and while resting after the active period from the ME estimates. During the daytime resting period, the birds were relatively inactive, and we assumed the rate of en- 


\section{The American Naturalist}

ergy expenditure to be $2 \times$ BMR (Kendeigh et al. 1977). Energy spent during the active period as estimated with this method was $86.5 \pm 24.8 \mathrm{~kJ}$ in the easy treatment and $73.6 \pm 26.6 \mathrm{~kJ}$ in the hard treatment. These figures were not significantly different from values estimated with the doubly labeled water method (see table 4; easy treatment: $\mathrm{T}^{+}=14, P=.53$; hard treatment: $\left.\mathrm{T}^{+}=7, P=.15\right)$. However, these estimates are less reliable than those obtained using doubly labeled water, as they include the assumption about metabolic rate outside the working period. For this reason, although the similarity of estimates is reassuring in our discussion of foraging currency, we will use the doubly labeled water estimates as a measure of energy expenditure during foraging time.

\section{Time Budgets}

Time in the active period was divided into perching time and travel time $\left(T_{\mathrm{T}}\right)$ and the latter was further divided into time walking $\left(T_{\mathrm{w}}\right)$ and time flying $\left(T_{\mathrm{f}}\right)$. Because of forced trials, the time spent walking each day was necessarily correlated to the time spent flying $\left(r_{\mathrm{s}}=0.68, P=\right.$ $.014, N=14$, Spearman rank correlation). However, the slope of these correlations depends on the subjects' relative preference between walking and flying, and the absolute amount of travel is under the birds' control. Of the $8 \mathrm{~h}$ available for foraging, birds in the easy treatment spent $7 \mathrm{~min} 47 \mathrm{~s} \pm 2 \mathrm{~min} 10 \mathrm{~s}(1.6 \%)$ flying and $16 \mathrm{~min}$ $27 \mathrm{~s} \pm 5 \mathrm{~min} 21 \mathrm{~s}(3.4 \%)$ walking, perching the rest of the time. In the hard treatment, the birds flew an average of $17 \mathrm{~min} 25 \mathrm{~s} \pm 5 \mathrm{~min} 35 \mathrm{~s}(3.6 \%)$ and walked $26 \mathrm{~min}$ $53 \mathrm{~s} \pm 9 \mathrm{~min} 31 \mathrm{~s}(5.6 \%)$, and perched the rest of the time. These values indicate that time available for foraging was not a constraint for total intake, and thus the variations in intake and body mass and the other observed changes cannot be explained as trivial consequences of the fact that food took more time to procure in the hard treatment. Our subjects had plenty of "free" time that they did not employ in foraging.

The birds were weighed after the foraging period was over, and this was followed by about $3 \mathrm{~h}$ during which no foraging was possible. Typically, after bathing and preening, they perched until the lights were switched off. Sampling by observation during this period showed only occasional flights and walks that lasted less than 1 min 32 s $(0.8 \%)$ on average.

\section{Relationships between Behavior and Intake}

We hypothesized that the relative preferences between the two foraging modes (walking: low gain rate and low expenditure; flying: high intake rate and high expenditure) could vary between treatments. Preferences between

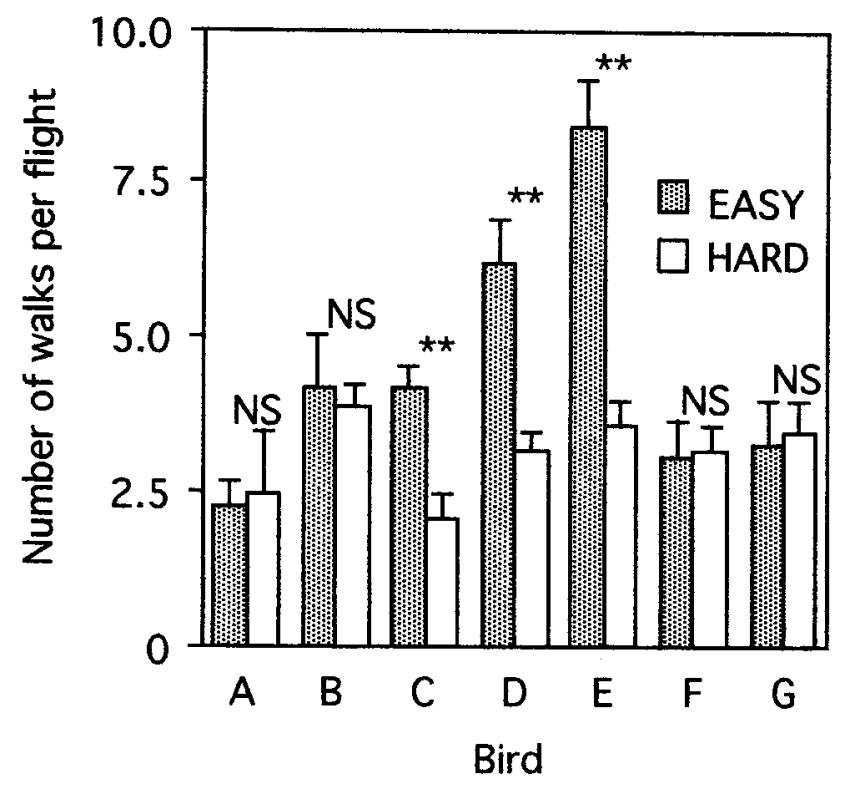

Figure 3: Number of walks per flight in easy (filled bars) and hard (open bars) treatments for each starling. Overall, there was no significant difference in number of walks per flight between treatments, but three birds changed number of walks per flight between treatments (birds $\mathrm{C}, \mathrm{D}$, and $\mathrm{E}, P<.01$, WilcoxonMann-Whitney test $W_{x}$ ).

foraging mode did reach stable values. We established this by visual inspection of the data and by computing the difference in mean number of walks per reward between consecutive days as a measure of this variability. If a bird is perfectly stable, its mean is 0 . If it has a persistent preference for either walking or flying, this difference would be some positive or negative integer. Differences in the number of walks per reward did not change significantly over the last $6 \mathrm{~d}$ in either the easy treatment (mean change $\pm 1 \mathrm{SD}=-0.21 \pm 0.41, P=.11$ ) or the hard treatment (mean change $\pm 1 \mathrm{SD}=-0.25 \pm 1.20$, $P=.29)$. The two flights per reward in the easy treatment generated equilibrium at $9 \pm 4$.1 walks per reward, while the $7.8 \pm 1.1$ flights per reward in the hard treatment were balanced against $24 \pm 6.3$ walks per reward.

Overall, even though there was a reduction from a mean of 4.5 to 3.1 walks per flight from the easy to the hard treatment, this difference was not statistically reliable $\left(\mathrm{T}^{+}=22, P=.11\right)$, but three birds ( $\mathrm{C}, \mathrm{D}$, and $\mathrm{E}$ ) showed a significant shift toward the expensive flying mode in the hard treatment. They walked circa 50\% fewer times per flight in the hard treatment than in the easy treatment (fig. 3). These same birds decreased their daily intake from easy to hard much less than the other birds (fig. 4). In other words, by shifting between foraging modes, they achieved a more stable intake between treatments than the other subjects. This strategic differ- 


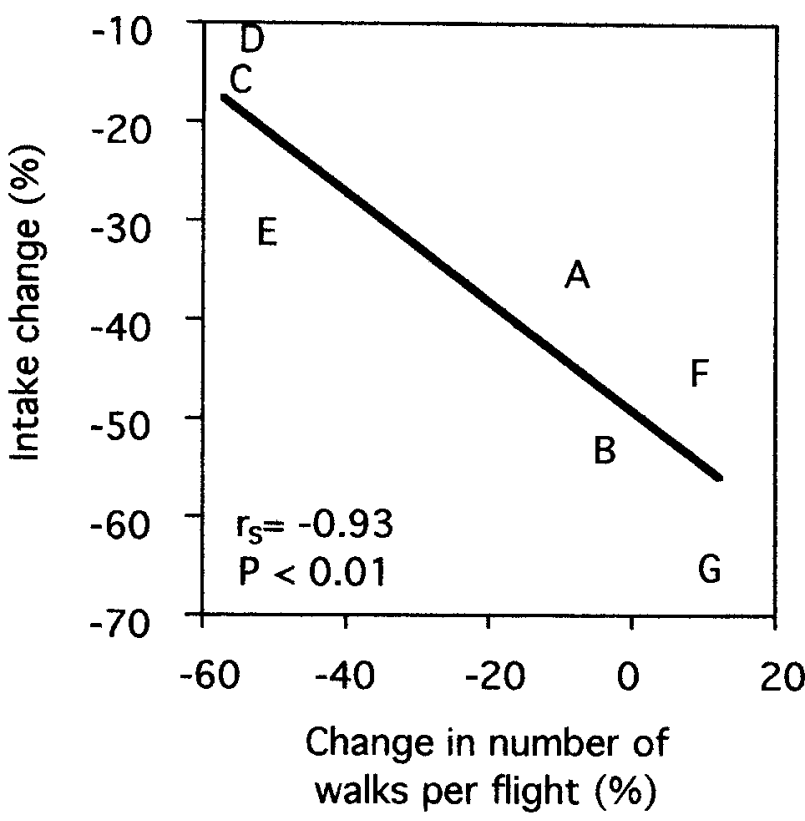

Figure 4: Relation between the difference in intake and in the number of walks per flight between the easy and the hard treatment. Differences are expressed as percentages, that is, [(hard - easy)/easy] $\times 100 \%$. Birds who did not modify their preference between foraging modes $(A, B, F$, and $G)$ lost more intake than the rest $(C, D$, and $E)$, which showed a greater bias toward flying in the hard treatment.

ence did not seem to vary along a continuum, because, when examined for all seven birds, the change in $\mathrm{BM}_{\mathrm{pm}}$ and the change in $\mathrm{BM}_{\mathrm{am}}$ between treatments were not correlated with the change in the number of walks per flight $\left(\mathrm{BM}_{\mathrm{pm}}: r_{\mathrm{s}}=-0.68, P>.10 ; \mathrm{BM}_{\mathrm{am}}: r_{\mathrm{s}}=0.14\right.$, $P>$.50). The bias between foraging modes was more variable in the easy treatment, with a coefficient of variation of $46 \%$ in number of walks per flight, as opposed to $26 \%$ in the hard treatment. This result is compatible with the presence of greater strategic flexibility under easier conditions and more stereotypic behavior under hard conditions. Most attempts to test optimal foraging models do take this into account by testing animals under relatively harsh conditions.

\section{Travel Costs}

The doubly labeled water measurements of daytime energy expenditure were also used to estimate the travel costs. Five of the seven birds increased the daytime energy expenditure per gram of body mass with travel time. We estimated travel costs from these variations and daytime energy expenditure (DTEE), using body mass as independent variable. A standard ANCOVA (fitted with generalized linear models implemented in GLIM soft- ware; Francis 1993), with bird as random factor and $\mathrm{BM}_{\mathrm{am}}$ and total travel time $\left(T_{\mathrm{T}}=T_{\mathrm{f}}+T_{\mathrm{w}}\right)$ as covariates, yielded

$$
\text { DTEE }=-146+3.03 \mathrm{BM}_{\mathrm{am}}+0.0178 \mathrm{~T}_{\mathrm{T}},
$$

where DTEE is in kilojoules, $\mathrm{BM}_{\mathrm{am}}$ in grams, and $T_{\mathrm{T}}$ in seconds. Coefficients of $\mathrm{BM}_{\mathrm{am}}$ and $T_{\mathrm{T}}$ were significant $(P<.05, t$-test $)$, but the constant was not different from 0 . The factor bird was not significant $(F=2.11$, df $=6$, $13, P=.21)$. The interaction of body mass with travel time was not included because it had been found previously to be nonsignificant $(F=0.01, \mathrm{df}=1,13, P=$ .84). This equation implies that for every second that starlings spent in travel, energy expenditure increased $17.8 \mathrm{~J}$. Following the arguments put forward by Flint and Nagy (1984) and by Wilson and Culik (1993), maintenance metabolism should be added to the incremental cost of travel. Intercepts of the regression lines for $T_{\mathrm{T}}=$ 0 were $64 \pm 13 \mathrm{~kJ}$ over the 8 -h foraging period in the easy treatment and $27 \pm 17 \mathrm{~kJ}$ in the hard treatment. Adding maintenance costs of $2.2 \pm 0.4 \mathrm{~W}$ and $0.9 \pm 0.6$ $\mathrm{W}$, respectively, yields estimated travel costs of $20.0 \pm 14$ $\mathrm{W}$ and $18.7 \pm 15 \mathrm{~W}$ in the easy and hard treatments. These are average rates of expenditure that include flying and walking. Next we separate these two components.

The travel cost estimated above includes energy spent walking and flying. Because $T_{\mathrm{T}}=T_{\mathrm{w}}+T_{\mathrm{f}}$, and $T_{\mathrm{w}}$ was correlated with $T_{\mathrm{f}}$, using an estimate of the cost of walking, we can subtract the energy spent walking from the travel cost (Wilson and Culik 1993) to estimate the flight cost. We estimated the cost of walking, defined as the increase in rate of expenditure of walking over resting $\left(E_{\mathrm{w}}, \mathrm{W}\right)$, with the equation $E_{\mathrm{w}}=\mathrm{BM} \star\left(5.6 \mathrm{BM}^{-0.246}+\right.$ 11.4 $\mathrm{BM}^{-0.285} v$ ), where $\mathrm{BM}$ is body mass in kilograms and $v$ is the walking velocity in meters/second (King 1985). The estimated walking cost was $1.63 \pm 0.07 \mathrm{~W}$ in the easy treatment $(2.24 \times \mathrm{BMR})$ and $1.59 \pm 0.11 \mathrm{~W}$ in the hard treatment $(3.35 \times \mathrm{BMR})$. Subtracting the energy spent walking from the estimated travel costs yields an estimated flight cost of $52.3 \pm 25.1 \mathrm{~W}$ in the easy treatment and $45.5 \pm 11.8 \mathrm{~W}$ in the hard treatment. These figures are remarkably high but still not significantly different from those estimated by Westerterp and Drent (1985) as $34 \pm 18 \mathrm{~W}$ for short flights $(<7 \mathrm{~m})$ in captive starlings. Notice that even if our estimate of walking costs were underestimates by a factor of 2, the estimates of flying cost would be $48.3 \pm 23.9 \mathrm{~W}$ for easy and $41.6 \pm 10.1 \mathrm{~W}$ for hard, which are still much higher than assumed in many foraging models. Short flights are very costly because they include substantial cost of acceleration and landing as well as being low velocity flights. Clearly, when incorporating flying costs in predictions of foraging currencies, it is crucial to use the costs for the 


\section{The American Naturalist}

typical flight distances in the environment and foraging mode being studied because flight costs depend substantially on this.

\section{Foraging Currencies}

In spite of the fact that the starlings spent the major portion of the day perching, the estimated energy expenditure rate during the foraging period in the hard treatment $(5.2 \times \mathrm{BMR})$ was high. Under those conditions, animals may be unable to increase expenditure, and one may expect them to choose among foraging options on the basis of their ratio of gains per unit of expenditure (efficiency), rather than net gains per unit of time (Kacelnik and Houston 1984; Stephens and Krebs 1986; Welham and Ydenberg 1993; Hedenström and Alerstam 1995 , p. 474). We can test if starlings choose between flying and walking on the basis of efficiency by calculating the relative efficiency and net rate of gain of both walking and flying. Whichever currency was used by the subjects, it should have been equalized among the two foraging modes at the ratio of walks per flight observed at the choice equilibrium (Krebs and Kacelnik 1984).

The fit of efficiency and net rate to the obtained indifference can be visualized by plotting the position of the walking and flying modes in a space of gross energy gain versus energy expenditure for efficiency and net energy gain versus time for net rate. If the animal is using either of these criteria, then walking and flying modes would lie on one straight line containing the origin. This can be seen for average values in figure 5, where we show the lines predicted by each currency for flying, which were imposed by our procedure and the position of the walking parameters that result from the birds' preferences.

Energetic efficiency was significantly greater walking than flying in both treatments for all starlings (13.8 \pm 4.2 walking vs. $4.3 \pm 0.4$ flying in easy; $12.0 \pm 2.0$ walking vs. $2.0 \pm 0.3$ flying in hard; $P<.02$ for both treatments). All subjects showed a greater preference for the expensive, high yield foraging mode than was necessary to equilibrate the energy efficiency of flying and walking. Had they been efficiency maximizers, they would have walked more often, thus requiring more walks per reward in the titration procedure and hence increasing the cost of walking as shown by the arrow in the figure. Thus, even though the birds were not constrained by time and were possibly constrained by rate of expenditure, efficiency does not explain the relative preference of foraging mode.

A similar test, when applied to net rate maximization, shows that starlings were closer to adjusting walking to flying according to this currency (fig. 5), showing no sig- nificant difference between predictions and observations. In the easy treatment, starlings obtained $18.6 \pm 1.9 \mathrm{~W}$ flying and $14.6 \pm 4.1 \mathrm{~W}$ walking $\left(\mathrm{T}^{+}=3, P=.08\right)$, while in the hard treatment they obtained $9.1 \pm 2.3 \mathrm{~W}$ flying and $11.8 \pm 1.8 \mathrm{~W}$ walking $\left(\mathrm{T}^{+}=24, P=.11\right)$. Neither efficiency nor net rate of gain explained the results when time between foraging cycles was included.

Because an important assumption in these calculations is the cost of flying, and our measured costs are higher than those currently used in the literature, we did a limited sensitivity analysis of the influence of the flight costs on our observation that the net rate of energy intake seemed close to predicting the observed equilibrium (fig. 6). We were particularly keen to check if the support for net rate of gain depended too strongly on our very high estimates of flying costs. Sensitivity analysis shows that smaller values of flight costs than those calculated by the doubly labeled water technique could change the statistical comparison between observed and predicted for the easy treatment but not for the hard treatment, while the reverse is true for flight costs greater than those we used. Our estimates of flight cost were $52.3 \mathrm{~W}$ in easy and 45.5 $\mathrm{W}$ in hard. A reduction of about $25 \%$ would be required to bring the flight cost in easy to below $40 \mathrm{~W}$ and make the observed and predicted values significantly different from each other, while no reasonable reduction would lead to a significant rejection of the net rate currency in hard. The lack of significant differences between observation and predictions (which of course does not imply identity) is thus fairly robust with respect to a possible overestimate of flying costs.

\section{Discussion}

In our experimental situation, starlings lived in a closed economy, obtaining virtually all their food from the experimental protocol, living permanently in their experimental aviaries and having flexibility in the temporal organization of their behavior during the day (Collier 1983). They could obtain food by either of two foraging modes, one requiring mostly flying and yielding a high rate of intake and the other mostly walking, with lower rate of returns. In each of two treatments, the amount of flying per food item was fixed, but the amount of walking per reward was adjusted, increasing when the bird chose the walking foraging mode and decreasing when it chose the flying mode. Our two treatments (easy and hard) differed in the amount of flying that the program required per reward, but the amount of walking in the alternative foraging mode was also different due to the choices of the birds. The number of flights per reward in hard was about four times the number of flights per re- 


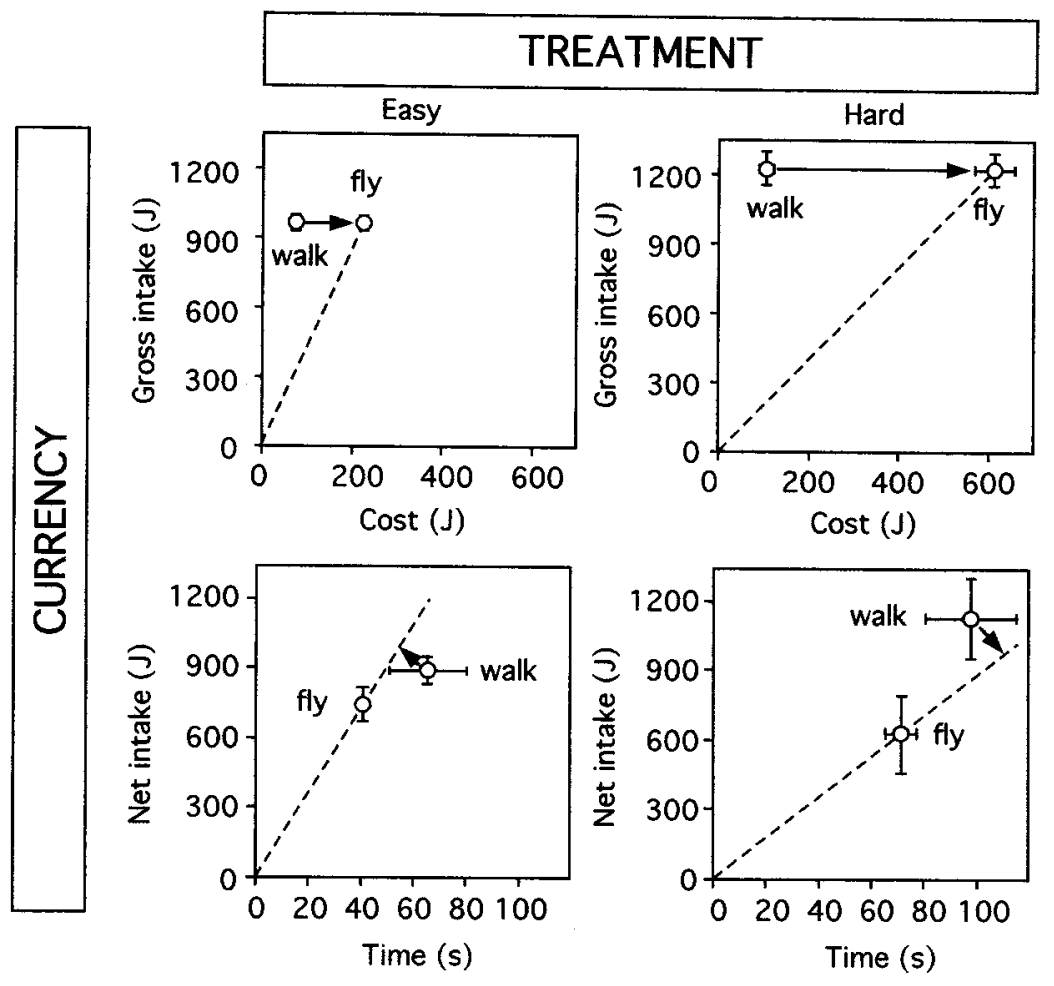

Figure 5: Graphical representation of the predictions for the walking foraging mode on the basis of different foraging currencies (efficiency and net energy gain) for the two treatments (left-hand panels = easy and right-hand panels = hard). The dotted lines represent the iso-currency lines, drawn using the flight option because flight effort per reward was fixed, while walking effort was determined according to the subjects' choice. Arrow tips indicate where the points for the walking option were expected to stabilize for each currency and treatment. Foraging choices were closer to the net energy predictions (bottom panels) than to the efficiency ones (top panels). Gross and net energy intakes are expressed per reward.

ward in easy. The starlings responded to the treatment differences with a suite of behavioral and physiological adaptations, which we summarize below by describing what was found in the hard treatment as compared with the easy treatment.

It was found that the total daily amount of foraging work was higher, that the extra work was not sufficient to equalize intake (table 1), and that the total expenditure over the 24-h cycle was lower (table 2). Body mass at any given time of day was lower, but the daily oscillation in body mass did not differ in absolute value, so that, proportionally, body mass showed greater daily variation in the hard treatment (fig. 2). Energy consumption overnight, as measured by respirometry, was lower (table 3), and feces' caloric density was lower, indicating greater utilization of the food (table 2). The birds were not constrained by time (under both conditions they spent more than $90 \%$ of the time perching).

In addition, it was found that energy expenditure rate expressed as multiples of BMR during the working period increased from $3.5 \times$ BMR in easy to $5.2 \times \mathrm{BMR}$ in hard (table 4) but did not differ over the 24-h period at about $2.4 \times$ BMR in both treatments (table 2). This effect includes differences in BMR and in daytime expenditure.

Other findings when the hard treatment was compared to the easy treatment were that between-subject variance in relative choice between walking and flying was lower, with a weak (marginally nonsignificant) shift to greater preference for flying in hard (fig. 4) and that the rate of expenditure during flying was very high in both treatments but decreased from $52.3 \mathrm{~W}$ in easy to $45.5 \mathrm{~W}$ in hard. This effect incorporates the change in BM. Finally, it was found that the relative preferences between walking and flying were incompatible with maximizing efficiency but not significantly different from maximizing net rate of gain per foraging cycle (fig. 5). Neither efficiency nor net rate of gain explained the results when time between foraging cycles was included.

These findings have various consequences. In the first place, they mean that the allocation of energy between work and other costs paid by keeping up body mass plays 


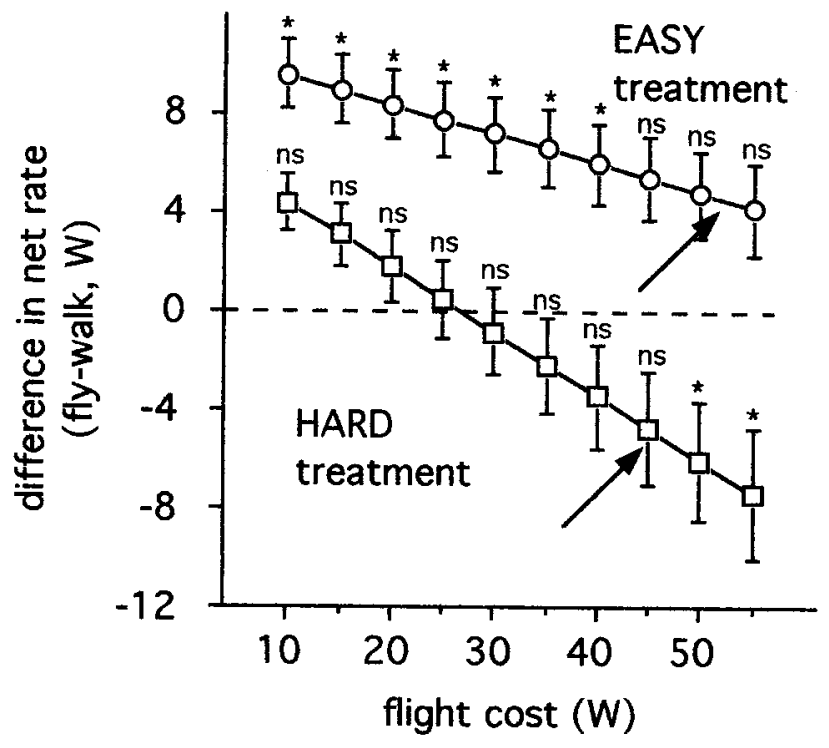

Figure 6: Sensitivity analysis of the effect of flight costs on the fit of net rate of energy intake. The mean ( \pm 1 SE, $n=7$ birds) difference between net rates of energy intake obtained flying and walking is calculated for the easy treatment (circles) and hard treatment (squares). Flight costs that generate significant differences are indicated by an asterisk $(P<.05$, Wilcoxon signed rank test). Arrows indicate the flight cost estimated for each treatment with the doubly labeled water technique.

an important role in coping with a leaner environment. The second consequence is that energy budgets can be very misleading when based on time budgets alone, that is, without additional knowledge on the compensating mechanisms used by the birds. We expand on these issues below.

\section{Energy Budget}

Paradoxically, total energy expenditure is lower in the hard treatment even though more work is done and energy expenditure rate expressed as multiples of BMR during the working period is higher. This is achieved by the savings made during the night and the nonforaging periods of the day. The savings result from a reduction in body mass combined with a reduction in mass-specific metabolism. A similar finding was made by Deerenberg et al. (1996) in zebra finches (Taeniopygia guttata) raising broods of manipulated size. Reductions in nighttime metabolic rate are often associated with hypothermia (Daan et al. 1989; Rashotte and Henderson 1988). Drops in heat production occur in a number of endothermic animals during periods of energetic emergency (Connors and Nickol 1991; Handrich et al. 1997), and in some passerines, they are observed when food intake is reduced (e.g., Chaplin 1976; Reinertsen and Haftorn 1984; see reviews of Reinertsen and Haftorn 1986; Reinertsen 1996). Since we did not measure body temperatures, we cannot confirm this point, but hypothermia as a result of turning down nocturnal metabolic rate is a plausible mechanism in this case as well.

\section{Time Budget}

The reductions in intake and body mass under the hard condition occur even though the birds spent approximately $90 \%$ of their time perching. Clearly, loss of foraging opportunity, which is the standard justification for models based on rate maximization (Stephens and Krebs 1986), was not the paramount factor in the birds' overall strategy because there were plenty of foraging opportunities not taken.

\section{Body Mass}

To discuss the variation in body mass itself, it is best to consider it as a strategic choice rather than as the outcome of simple homeostatic mechanisms. In general, the choice of body mass should be determined by the tradeoffs between the advantages of high levels of reserves and the disadvantages of carrying extra weight around. Increases in body mass act as an insurance against unpredictable variance in overnight temperature or in future food availability, but they cause increases in flying and maintenance costs (Daan et al. 1990; McNamara and Houston 1990; Nörberg 1990; Houston 1993; Piersma et al. 1996). Extra body mass also makes birds less maneuverable and hence more vulnerable to predators (Moreno 1989; Witter and Cuthill 1993; Gosler et al. 1995; Metcalfe and Ure 1995). The reduction in body mass that we found is dramatic compared to the typical body mass for this species in the wild. The resulting energy savings of the birds were considerable judging from the fact that daytime energy expenditure in the two treatments was not significantly different between the easy and the hard treatment yet working time doubled. The decreased body mass, however, was not responsible for all of these savings: our subjects in the hard treatment also had a lower mass specific metabolic rate at night. One possible incentive to reduce expenditure by mass reduction during the working period in the hard treatment is that the birds during this 8-h period were expending energy at rates that were greater than previous estimations of energy expenditure in starlings foraging (e.g., $2.5 \times$ BMR; Westerterp and Drent 1985). This was not so in the easy treatment, and hence, the putative costs of high energy expenditure rate may have favored a strategic reduction in body mass. 


\section{Energy Utilization}

The starlings modified their food utilization efficiency, producing feces with lower energy density when food was harder to obtain. We cannot establish the mechanism for this response because there was occasional coprophagia, and this could have differed between treatments. Foodrationed starlings have been observed to eat feces (Meijer and Langer 1995), but no connection has been established with feces' caloric density. Our treatment of feces does not discriminate between products that never crossed the gut wall and products of renal excretion. However, it is known that starlings can change intestinal morphology according to diet and that they have the ability to improve intestinal hydrolases in response to changes in nutrient intake (Al Jaborae 1979; Martinez del Rio et al. 1995). More research in digestive adaptability is necessary because Levey and Karasov (1994) found no changes in retention times between starlings fed on crickets or fruit, while Connors and Nickol (1991) reported no changes in assimilation efficiency associated with stress induced by parasitism with Plagiorhynchus cylindraceus (Acanthocephala).

\section{Why Starlings Spent Most of the Time Perching}

In spite of the fact that the rate of energy gain was severely constrained in the hard treatment, our birds spent most of their time perching. This is a major paradox from the point of view of maximization of rate of gain because under both conditions and foraging modes, foraging yielded positive net energy gain. More work would have increased net daily energy gains, but the birds chose not to do it. There may be several reasons for this. First, inactivity is necessary if animals approach their maximum aerobic capacity. When muscles work at a very high rate, anaerobiosis may be used to release energy for work, but then lactic acid accumulates and periods of inactivity are required to eliminate it (Schmidt-Nielsen 1991). The starlings in our system may have been working above their aerobic capacity because the cost of the short flights was well above the common value for longer flights as measured in the field. Several studies on birds foraging in expensive ways have found a relationship between expensive foraging and subsequent pauses for physiological recovery (e.g., Ydenberg and Forbes 1988; Ydenberg and Guillemette 1991; Monaghan et al. 1994). For instance, central place-foraging starlings paused for longer on top of their nests after longer or more heavily laden trips (Kacelnik and Cuthill 1987). Anaerobic work due to the high cost of short flights may be part of the reason why starlings in the hard treatment foraged actively no more than $10 \%$ of the time available $(3.6 \%$ fly- ing and $5.6 \%$ walking), while breeding starlings in the wild may spend 12\% (Ricklefs and Williams 1984) to 24\% (Tinbergen 1981) of the time available for foraging in flight while provisioning their nests.

A second possibility is that starlings were facing a digestive or energy-processing bottleneck (Sibly and Calow 1986; Kersten and Piersma 1987). Our experimental birds spent $144 \mathrm{~kJ}$ per day in the easy and $107 \mathrm{~kJ}$ in the hard treatment. This is low when compared to the $233 \mathrm{~kJ}$ per day that starlings on average spent while feeding young in the field (Westerterp and Drent 1985) or with the 233-260 kJ per day calculated as their maximum daily energy expenditure (Kirkwood 1983; Daan et al. 1990). There is, however, one major difference between these field situations and the situation we studied: the working day length. In the field, during the breeding season, starlings work for about $15 \mathrm{~h}$, while in the laboratory we used working day length more typical for self-feeding starlings in the British or Dutch winter - that is, about 8 h. This means that the energy turnover rate was similar in the two situations: $18 \mathrm{~kJ} / \mathrm{h}$ or $13.4 \mathrm{~kJ} / \mathrm{h}$ for easy and hard treatment, respectively, while the estimates from the wild in spring are $15.4 \mathrm{~kJ} / \mathrm{h}$ (Tinbergen 1981). These figures are closer to each other than those for absolute rate of expenditure, but the puzzle remains because the lowest energy expenditure rate is observed under the hard treatment, precisely when one might have expected an increase due to the increased working effort. These arguments remain speculative because little is known of the timescale over which energy turnover constraints may operate. A digestive, rather than expenditure, bottleneck cannot be dismissed because the birds in the hard treatment were lighter and consequently may also have reduced the size of their digestive tract.

Third, an entirely different sort of explanation may be considered, based not on physiological considerations but on cognitive, psychological architecture. It is well known from studies in the operant psychology literature that the details of reward schedules have a major impact on the responses of working animals. Most of these studies are in open economies, that is, in cases where hungry animals are allowed to work for brief periods of time to obtain small amounts of food and are later fed outside the experimental situation. Under these conditions, there is a very reliable difference between animals working in fixed ratio (FR) schedules and those working on variable ratio schedules (VR). In an FR $n$ schedule, a reward requires $n$ responses in every trial, while in a $\operatorname{VR} n$ schedule, it takes $n$ trials on average, but the actual number is variable between trials. In a typical $\operatorname{VR} n$ schedule, every response has a probability $1 / n$ of resulting in a reward. Although average costs are the same when evaluated over many rewards, from the point of view of the animal, the 


\section{The American Naturalist}

two procedures introduce differences in reward expectation for individual responses. In an FR $n$ schedule, responses other than the $n$th one after a reward are never reinforced, and, hence, motivation to start working after a reward is low. In a VR $n$ schedule, however, regardless of the value of $n$, every response, including the first one, has the same probability of yielding food. Consistent with this, animals in FR schedules tend to show a long postreinforcement pause, often proportional to the value of $n$, while those in VR schedules do not show these pauses and work at an overall higher rate of responding (Staddon 1983). We used FR schedules (the ratios for walking were adjusted with time but were deterministically fixed from trial to trial). If the observations under open economy apply to our closed economy situation, the lower rate of work in the hard condition may have a psychological, rather than a physiological, explanation because, in the hard treatment, the aversive connotation of the initial responses after reward was greater than in the easy treatment, and, hence, the motivation to work at the beginning of a foraging cycle should have been lower. This speculation is easily discernible with an appropriate experiment in which an FR $n$ and a VR $n$ condition are compared in a closed economy. The most relevant evidence available is that of Johnson and Collier (1994). They tested rats in closed economy under fixed and variable schedules and found no overall effect on daily consumption, thus suggesting that global energetic factors can override local, response-by-response ones, but their experiments are different from ours in a substantial feature: their animals could choose the size of each meal after ending each cycle instead of having access to a single reward as in our case. Thus, the effects of the differences between the variable and fixed schedules in their case could have been absorbed by meal size. The matter should soon be settled experimentally.

\section{Foraging Currencies}

The two more obvious foraging currencies when only energetic arguments are used are the ratios of net gains over time (net rate) and of gains per unit of expenditure (efficiency). One would expect animals to use either of those when the respective denominator is the constraining factor. If foraging time is limiting, then the best strategy is to maximize net rate, to avoid the loss of foraging opportunities. If energy turnover is limiting, then one expects the maximization of efficiency as this makes better use of each unit of expenditure. Several of our previous arguments suggest that rate of energy turnover may have been important, and thus efficiency should have been a strong candidate currency (Stephens and Krebs 1986; Ydenberg et al. 1994; Hedenström and Alerstam
1995; Houston 1995). We found that the currency that best explained the relative preference between walking and flying was the maximization of net rate of gain including only the times actively used for foraging-that is, using as the denominator the time taken per foraging cycle, from the time of the first flight till the completion of the cycle.

This result, although inconsistent with the rationale of net rate maximization because it does not fit well with the principle of lost opportunity, has also been found in experiments in which starlings chose between individual food items associated with different programmed delays (Bateson and Kacelnik 1996; Kacelnik and Bateson 1996). Cognitive variables such as attention, motivation, and the conditioning process by which animals are tested probably play a role of greater importance than usually considered by most optimal foraging modelers.

\section{Final Remarks}

Our study serves three purposes. First, we provide a number of specific facts about the behavioral and physiological adaptations of starlings to changing levels of food availability. Second, we show that a narrow behavioral approach such as frequently employed within foraging ecology research may be misleading because it may obscure the wide variety of adaptations used by foragers to cope with their ecological demands. Behavior should be seen as only one pawn in the game played by animals against their environment. Third, we illustrate our claim that optimality modeling when embedded in a more comprehensive perspective may be a valuable heuristic tool to examine the significance of each observation. Indeed, we believe that ecological, evolutionary, physiological, and cognitive dimensions must be combined to account for animals' interaction with their habitat. Unfortunately (or perhaps happily), in real-life biology, there is no escape from complexity.

\section{Acknowledgments}

The Department of Chronobiology of the University of Groningen gave access to the respirometer and bomb calorimeter. H. Visser provided material and intellectual insight on the procedures involving doubly labeled water. We would like to thank G. J. Klop and V. van Maanen for participating in data collection during part of the experiment. S. Daan, B. Ens, L.-A. Giraldeau, S. Lane, K. A. Nagy, T. Piersma, R. E. Ricklefs, A. Thomas, J. Viñuela, and Y. Winter provided constructive criticism of earlier versions. The project was partially funded by the Royal Society (United Kingdom), the Welcome Trust (United Kingdom; research grant 046101 to A.K.), and Ministerio 
de Educación y Ciencia (MEC) of Spain. L.M.B. was supported with a postdoctoral grant from MEC and also, during the last part of the study, by the project PB920044-CO2 of Dirección General de Investigación en Ciencia y Tecnología (DGICYT).

\section{Literature Cited}

Al Jaborae, F. F. 1979. The influence of diet on the gut morphology of the starling (Sturnus vulgaris). Ph.D. diss. Oxford University, Oxford.

Aschoff, J., and M. Pohl. 1970. Der Ruheumsatz von Vögeln als funktion der tageszeit und der Körpergrösse. Journal für Ornithologie 111:38-47.

Bateson, M., and A. Kacelnik. 1996. Rate currencies and the foraging starling: the fallacy of the averages revisited. Behavioral Ecology 7:341-352

Biebach, H. 1979. Energetik des Brütens beim Star (Sturnus vulgaris). Journal für Ornithologie 120:121-138.

- 1981. Energetic costs of incubation on different clutch sizes in starlings (Sturnus vulgaris). Ardea 69: $141-142$.

-1984. Effect of clutch size and time of day on the energy expenditure of incubating starlings (Sturnus vulgaris). Physiological Zoology 57:26-31.

Bryant, D. M., and P. Tatner. 1991. Intraspecies variation in avian energy expenditure: correlates and constraints. Ibis 133:236-245.

CeNeS Cognition. 1990. SPIDER, version 1. CeNeS, Cognition, Cambridge.

Chaplin, S. B. 1976. The physiology of hypothermia in the black-capped chickadee, Parus atricapillus. Journal of Comparative Physiology 112:335-344.

Collier, G. H. 1983. Life in a closed economy: the ecology of learning and motivation. Advances in the Analysis of Behaviour 3:223-274.

Connors, V. A., and B. B. Nickol. 1991. Effects of Plagiorhynchus cylindraceus (Acanthocephala) on the energy metabolism of adult starlings, Sturnus vulgaris. Parasitology 103:395-402.

Daan, S., D. Masman, A. Strijkstra, and S. Verhulst. 1989. Intraspecific allometry of basal metabolic rate: relations with body size, temperature, composition, and circadian phase in the Kestrel Falco tinnunculus. Journal of Biological Rhythms 4:267-286.

Daan, S., D. Masman, and A. Groenewold. 1990. Avian basal metabolic rates: their association with body composition and energy expenditure in nature. American Journal of Physiology 259:R333-R340.

Deerenberg, C. M., C. H. Dekogel, and G. F. J. Overkamp. 1996. Costs of reproduction in the zebra finch Taeniopygia guttata: manipulation of brood size in the laboratory. Avian Biology 27:321-326.
Diamond, J. M., and K. A. Hammond. 1992. The matches, achieved by natural selection, between biological capacities and their natural loads. Experientia (Basel) 48:551-557.

Dmi'el, R., and D. Tel-Zur. 1985. Heat balance of two starling species (Sturnus vulgaris and Onychognathus tristrami) from temperate and desert habitats. Journal of Comparative Physiology 155:395-402.

Drent, R. H., and S. Daan. 1980. The prudent parent: energetic adjustments in avian breeding. Ardea 68:225252.

Dykstra, C. R., and W. H. Karasov. 1992. Changes in gut structure and function of house wrens (Troglodytes aedon) in response to increased energy demands. Physiological Zoology 65:422-442.

Flint, E. M., and K. A. Nagy. 1984. Flight energetics of free living sooty terns. Auk 101:288-294.

Francis, R. A. 1993. The GLIM system manual, release 4 ed. Clarendon, Oxford.

Gosler, A. G., J. J. D. Greenwood, and C. M. Perrins. 1995. Predation risk and the cost of being fat. Nature (London) 377:621-623.

Handrich, Y., R. M. Bevan, J. B. Charrassin, P. J. Butler, K. Pütz, A. J. Woakes, J. Lage, and Y. Le Maho. 1997. Hypothermia in foraging king penguins. Nature (London) 388:64-67.

Hedenström, A., and T. Alerstam. 1995. Optimal flight speed of birds. Philosophical Transactions of the Royal Society London B, Biological Sciences 348:471-487.

Hill, R. W. 1972. Determination of oxygen consumption by use of the paramagnetic oxygen analyser. Journal of Applied Physiology 33:261-263.

Houston, A. I. 1987. Optimal foraging by parent birds feeding dependent young. Journal of Theoretical Biology 124:251-274.

- 1993. The efficiency of mass loss in breeding birds. Proceedings of the Royal Society of London B, Biological Sciences 254:221-225.

- 1995. Energetic constraints and foraging efficiency. Behavioral Ecology 6:393-396.

Johnson, D. F., and G. H. Collier. 1994. Meal patterns of rats encountering variable food procurement cost. Animal Behaviour 47:1279-1287.

Kacelnik, A. 1984. Central place foraging in starlings (Sturnus vulgaris). I. Patch residence time. Journal of Animal Ecology 53:283-299

Kacelnik, A., and M. Bateson. 1996. Risky theories: the effects of variance on foraging decisions. American Zoologist 36:402-434.

Kacelnik, A., and I. C. Cuthill. 1987. Starlings and optimal foraging theory: modelling in a fractal world. Pages 303-333 in A. C. Kamil, J. R. Krebs, and H. R. Pulliam, eds. Foraging behavior. Plenum, New York. 
Kacelnik, A., and A. I. Houston. 1984. Some effects of energy costs on foraging strategies. Animal Behaviour 32:609-614.

Kacelnik, A., J. R. Krebs, and B. J. Ens. 1986. Foraging in a changing environment: an experiment with starlings (Sturnus vulgaris). Pages 63-87 in M. L. Commons, A. Kacelnik, and S. J. Shettleworth, eds. Quantitative analyses of behavior. Erlbaum, Mahwah, N.J.

Karasov, W. H. 1986. Energetics, physiology and vertebrate ecology. Trends in Ecology \& Evolution 1:100104.

. 1990. Digestion in birds: chemical and physiological determinants and ecological implications. Pages 391-415 in M. L. Morrison, C. J. Ralph, J. Verner, and J. R. Jehl, eds. Avian foraging: theory, methodology, and applications. Allen, Lawrence, Kans.

Kendeigh, S. C., V. R. Dolnik, and V. M. Gavrilov. 1977. Avian energetics. Pages 127-204 in J. Pinowski and S. C. Kendeigh, eds. Granivorous birds in ecosystems. Cambridge University Press, Cambridge.

Kersten, M., and T. Piersma. 1987. High levels of energy expenditure in shorebirds: metabolic adaptations to an energetically expensive way of life. Ardea 75:175187.

King, J. R. 1985. The energy requirements of terrestrial locomotion in birds. Pages 404-408 in Acta XVIII Congressus Internationalis Ornithologici, Moscow.

Kirkwood, J. A. K. 1983. A limit to metabolizable energy intake in mammals and birds. Comparative Biochemistry and Physiology A, Comparative Physiology 75: $1-3$.

Koops, M. A., and L. A. Giraldeau. 1996. Producerscrounger foraging games in starlings: a test of ratemaximising and risk-sensitive models. Animal Behaviour 51:773-783.

Krebs, J. R., and A. Kacelnik. 1984. Time horizons of foraging animals. Annals of the New York Academy of Sciences 423:278-291.

Levey, D. J., and W. H. Karasov. 1994. Gut passage of insects by European starlings and comparison with other species. Auk 111:478-481.

Lifson, N., and R. McClintock. 1966. Theory of use of the turnover rates of body water for measuring energy and material balance. Journal of Theoretical Biology 12:4674.

Martinez del Rio, C., K. E. Brugger, J. L. Rios, M. E. Vergara, and M. Witmer. 1995. An experimental and comparative study of dietary modulation of intestinal enzymes in European starlings (Sturnus vulgaris). Physiological Zoology 68:490-511.

Masman, D. 1986. The annual cycle of the kestrel, Falco tinnunculus, a study in behavioural energetics. Ph.D. diss. University of Groningen, Groningen.

Masman, D., and M. Klaassen. 1987. Energy expenditure for free flight in trained and free living kestrels. Auk 104:603-616.

Masman, D., S. Daan, and H. J. A. Beldhuis. 1988. Ecological energetics of the kestrel: daily energy expenditure throughout the year based on time-energy budget, food intake and doubly labeled water methods. Ardea 76:64-81.

Mauer, A. 1996. Energetics of avian foraging. Pages 250279 in C. Carey, ed. Avian energetics and nutritional ecology. Chapman \& Hall, New York.

McNamara, J., and A. I. Houston. 1990. The value of fat reserves and the tradeoff between starvation and predation. Acta Biotheoretica 38:37-61.

Meijer, T., and U. Langer. 1995. Food availability and egg-laying of captive European starling. Condor 97: 718-728.

Metcalfe, N. B., and S. E. Ure. 1995. Diurnal variation in flight performance and hence potential predation risk in small birds. Proceedings of the Royal Society of London B, Biological Sciences 261:395-400.

Monaghan, P., P. Walton, S. Wanless, J. D. Uttley, and M. D. Burns. 1994. Effects of prey abundance on the foraging behaviour, diving efficiency and time allocation of breeding guillemots Uria aalgae. Ibis 136:214222.

Moore, F. R., and P. A. Simm. 1985. Migratory disposition and choice of diet by the yellow-rumped warbler (Dendroica coronata). Auk 102:820-826.

Moreno, J. 1989. Strategies of mass change in breeding birds. Biological Journal of the Linnean Society 37: 297-310.

Nagy, K. A. 1980. $\mathrm{CO}_{2}$ production in animals: an analysis of the potential errors in doubly labeled water method. American Journal of Physiology 238:R466-R473.

Nörberg, U. M. 1990. Vertebrate flight. Springer, Berlin. Piersma, T., R. Bruinzeel, R. Drent, M. Kersten, J. van der Meer, and P. Wiersma. 1996. Variability in basal metabolic rate of a long-distance migrant shorebird (red knot, Calidris canutus) reflects shifts in organ sizes. Physiological Zoology 69:191-217.

Rashotte, M. E., and R. P. Henderson. 1988. Coping with rising food costs in a closed economy: feeding behavior and nocturnal hypothermia in pigeons. Journal of Experimental Analysis of Behaviour 50:441-456.

Reinertsen, R. E. 1996. Physiological and ecological aspects of hypothermia. Pages 125-157 in C. Carey, ed. Avian energetics and nutritional ecology. Chapman \& Hall, New York.

Reinertsen, R. E., and S. Haftorn. 1984. The effect of 
short-time fasting on metabolism and nocturnal hypothermia in the willow tit Parus montanus. Journal of Comparative Physiology 154:23-28.

. 1986. Different metabolic strategies of northern birds for nocturnal survival. Journal of Comparative Physiology 156:655-663.

Ricklefs, R. E. 1996. Avian energetics, ecology, and evolution. Pages 1-30 in C. Carey, ed. Avian energetics and nutritional ecology. Chapman \& Hall, New York.

Ricklefs, R. E., and J. B. Williams. 1984. Daily energy expenditure and water-turnover rate of adult European starlings (Sturnus vulgaris) during the nesting cycle. Auk 101:707-716.

Ricklefs, R. E., M. Konarzewski, and S. Daan. 1996. The relationship between basal metabolic rate and daily energy expenditure in birds and mammals. American Naturalist 147:1047-1071.

Schmid-Hempel, P., A. Kacelnik, and A. I. Houston. 1985. Honeybees maximize efficiency by not filling their crop. Behavioral Ecology and Sociobiology 17: 61-66.

Schmidt-Nielsen, K. 1991. Animal physiology: adaptation and environment. Cambridge University Press, London.

Schoeller, D. A., E. van Santen, D. W. Peterson, W. Dietz, J. Jaspan, and P. D. Klein. 1980. Total body water measurement in humans with ${ }^{18} \mathrm{O}$ and ${ }^{2} \mathrm{H}$ labeled water. American Journal of Clinical Nutrition 33: 2682-2693.

Sibly, R. M., and P. Calow. 1986. Physiological ecology. Blackwell Scientific, Oxford.

Siegel, S., and N. J. Castellan. 1988. Nonparametric statistics for the behavioral sciences. McGraw-Hill, Singapore.

Staddon, J. E. R. 1983. Adaptive behavior and learning. Cambridge University Press, New York.

Stephens, D. W., and J. R. Krebs. 1986. Foraging theory. Princeton University Press, Princeton, N.J.

Tiebout, H. M. 1991. Daytime energy management by tropical hummingbirds: responses to foraging constraint. Ecology 72:839-851.

Tinbergen, J. M. 1981. Foraging decisions in starlings (Sturnus vulgaris). Ardea 69:1-67.
Weiner, J. 1987. Maximum energy assimilation rates in the Djungarian hamster (Phodopus sungorus). Oecologia (Berlin) 72:297-302.

- 1992. Physiological limits to sustainable energy budgets in birds and mammals: ecological implications. Trends in Ecology \& Evolution 7:384-388.

Welham, C. V. J., and R. C. Ydenberg. 1993. Efficiencymaximizing flight speeds in parent black terns. Ecology 74:1893-1901.

Westerterp, K., and R. Drent. 1985. Energetic costs and energy-saving mechanisms in parental care of free-living passerine birds as determined by the $\mathrm{D}_{2}{ }^{18} \mathrm{O}$ method. Pages 392-398 in XVIII Congressus Internationalis Ornithologici, Moscow.

Williams, J. B. 1985. Validation of the doubly-labelled water technique for measuring energy metabolism in starlings and sparrows. Comparative Biochemistry and Physiology A, Physiology 80:349-353.

Williams, J. B., and K. A. Nagy. 1984. Validation of the doubly-labeled water technique for measuring energy in savannah sparrows. Physiological Zoology 57:325328.

Wilson, R. P., and B. M. Culik. 1993. Activity-specific metabolic rates from doubly labeled water studies: are activity costs underestimated? Ecology 74:1285-1287.

Witter, M. S., and I. C. Cuthill. 1993. The ecological costs of avian fat storage. Philosophical Transactions of the Royal Society of London B, Biological Sciences 340: 73-92.

Ydenberg, R. C., and L. S. Forbes. 1988. Diving and foraging in the western grebe. Ornis Scandinavica 19: 129-133.

Ydenberg, R. C., and M. Guillemette. 1991. Diving and foraging in common eider. Ornis Scandinavica 22: 349-354.

Ydenberg, R. C., C. V. J. Welham, R. Schmid-Hempel, P. Schmid-Hempel, and G. Beauchamp. 1994. Time and energy constraints and the relationships between currencies in foraging theory. Behavioral Ecology 5:28-34.

Associate Editor: John A. Byers 